This item was submitted to Loughborough's Research Repository by the author.

Items in Figshare are protected by copyright, with all rights reserved, unless otherwise indicated.

\title{
Confirmatory factor analysis of the Sport Emotion Questionnaire in organisational environments
}

PLEASE CITE THE PUBLISHED VERSION

http://dx.doi.org/10.1080/02640414.2014.955520

PUBLISHER

(C) Taylor and Francis

\section{VERSION}

AM (Accepted Manuscript)

\section{PUBLISHER STATEMENT}

This work is made available according to the conditions of the Creative Commons Attribution-NonCommercialNoDerivatives 4.0 International (CC BY-NC-ND 4.0) licence. Full details of this licence are available at: https://creativecommons.org/licenses/by-nc-nd/4.0/

\section{LICENCE}

CC BY-NC-ND 4.0

\section{REPOSITORY RECORD}

Arnold, Rachel, and David Fletcher. 2019. "Confirmatory Factor Analysis of the Sport Emotion Questionnaire in Organisational Environments". figshare. https://hdl.handle.net/2134/20956. 
Confirmatory Factor Analysis of the Sport Emotion

Questionnaire in Organizational Environments

Rachel Arnold and David Fletcher

Loughborough University, United Kingdom

Author Note

Rachel Arnold and David Fletcher, School of Sport, Exercise, and Health Sciences, Loughborough University, United Kingdom.

Rachel Arnold is now at the Department for Health, University of Bath, United Kingdom. We thank Kevin Daniels (University of East Anglia) for his advice about data analysis procedures. Correspondence concerning this article should be addressed to Rachel Arnold, Department for Health, University of Bath, Claverton Down, Bath, BA2 7AY, United Kingdom. Telephone: 4412-2538-5107. Fax: 4412-2538-3833. Email: $\underline{\text { R.S.Arnold@bath.ac.uk }}$ 


\begin{abstract}
The Sport Emotion Questionnaire (SEQ) (Jones, M. V., Lane, A. M., Bray, S. R., Uphill, M., \& Catlin, J. (2005). Development and validation of the SEQ. Journal of Sport and Exercise Psychology, 27, 407-431) was developed and initially validated to assess sport performers' precompetitive emotions. The purpose of this study was to test the factor structure of the SEQ in a different environment (viz. organisational) and at a different time point (viz. the past month). A further aim was to examine if the SEQ was invariant across different groups of sport performers. A diverse sample of athletes $(n=1277)$ completed the questionnaire. Fit indices from confirmatory factor analyses provided partial support for the hypothesised measurement model, with equal or better fit demonstrated than evident in initial validation. The comparative fit index values were above acceptable guidelines for all factors at subscale level. Evidence was also found for the invariance of the SEQ across different groups. Overall, the findings support the reliability and validity of the SEQ as a measure of the emotions experienced by sport performers in an organisational environment during the past month.
\end{abstract}

Keywords: affect, psychometric, response, stress, validation 
Confirmatory Factor Analysis of the Sport Emotion Questionnaire in Organisational Environments The research conducted on human emotion over the past century has developed multiple definitions of the concept (Duffy, 1934; Gendron, 2010). Despite these various meanings, there appears to be a consensus forming about the function and structure of emotions (cf. Izard, 2010). Izard (2010) concluded that an emotion can function to motivate cognition and action, organise responses and monitor or assess the significance of events; and its structure comprises a response system to events, a feeling state and expression of behaviour. Within the field of sport psychology, emotions have become a popular research topic, partly due to the effects they can have on psychological- related processes but also, importantly, due to the effects they can have on sport performance (Hanin, 2000; Jones \& Uphill, 2011; Lazarus, 2000; Vallerand, 1983). In a sport performer's environment, emotions can arise from appraisals of a wide range of events; however, sport psychology research has typically focused on emotional responses to competition-related stimuli (Hanin, 2000, 2007; Vallerand \& Blanchard, 2000). In the competitive environment, researchers have found that sport performers experience an array of different emotions, including happiness, excitement, relief, pride, anger, anxiety, dejection, guilt and shame (see, e.g. Brunelle, Janelle, \& Tennant, 1999; Jackson, 2000; Martinent, Campo, \& Ferrand, 2012; Raglin \& Hanin, 2000).

Although researchers have traditionally focused on competitive emotions, studies are beginning to emerge that highlight examples of a sport performer's emotional responses to his or her organisational environment (see, e.g. Fletcher, Hanton, \& Wagstaff, 2012; Wagstaff, Fletcher, \& Hanton, 2012). For example, Fletcher et al. (2012) reported that sport performers experience anger, anxiety, disappointment, distress, happiness, hope, relief, reproach and resentment in response to organisational-related events and situations. It is important that researchers continue to investigate emotional responses in organisational environments because it has been suggested that 
emotions may act as a pivotal mediating factor between organisational events and undesirable outcomes (cf. Fletcher, Hanton, \& Mellalieu, 2006), such as impaired preparation for and performance at major competitions (Gould, Guinan, Greenleaf, Medbery, \& Peterson, 1999), overtraining (Meehan, Bull, Wood, \& James, 2004), burnout (Tabei, Fletcher, \& Goodger, 2012) and dysfunctional psychological health and well-being (Noblet, Rodwell, \& McWilliams, 2003).

A further rationale for investigating the organisational environment is the numerous demands that performers encounter within this context in competitive sport. To elaborate, in a research synthesis of 34 studies, Arnold and Fletcher (2012b) identified 640 distinct organisational stressors that sport performers encounter. These demands were organised in a taxonomic classification, comprising four main categories: leadership and personnel issues, cultural and team issues, logistical and environmental issues, and performance and personal issues. Leadership and personnel issues included the coach's behaviours and interactions, the coach's personality and attitudes, external expectations, support staff, sports officials, spectators, media, performance feedback and the governing body. Cultural and team issues included teammates' behaviours and interactions, communication, team atmosphere and support, teammates' personality and attitudes, roles, cultural norms and goals. Logistical and environmental issues included facilities and equipment, selection, competition format, structure of training, weather conditions, travel, accommodation, rules and regulations, distractions, physical safety and technology. Performance and personal issues included injuries, finances, diet and hydration, and career transitions. Evidence suggests that athletes experience and recall more stressors associated with the sport organisation than with the competitive environment (Hanton, Fletcher, \& Coughlan, 2005). In view of these observations, it is likely that in the situations where a performer is encountering an organisational demand (and not a competitive demand), the emotions associated with the organisational 
environment will explain greater variance in performance and wellbeing than those associated with the competitive environment (since there is no competitive demand to respond to). The potential impact that the emotions experienced in organisational contexts can have on performance and wellbeing underscores the importance of having a measure that can assess such emotions in a reliable and valid manner.

Various measures have been developed for researchers and practitioners to assess the presence of a single emotion in competitive sport (see, e.g. Martens, Burton, Vealey, Bump, \& Smith, 1990; Maxwell \& Moores, 2007). To assess a broader range of (positive and negative) emotions, Jones, Lane, Bray, Uphill, and Catlin (2005) developed the Sport Emotion Questionnaire (SEQ). It is evident that a number of theories were considered when developing the SEQ. To elaborate, Jones et al. (2005) drew from Frederickson's (2001) broaden and-build theory to define the concept of emotion, Lane and Terry's (2000) conceptual model to distinguish between emotion, mood and affect, and appraisal theories of emotion (cf. Lazarus, 1999; Lazarus \& Folkman, 1984) to provide a foundation for understanding how discrete emotions are differentiated. The 22-item SEQ consists of five subscales which represent the presence of pre-competition anger, anxiety, dejection, excitement and happiness emotions that athletes experience. Jones et al. (2005) chose these five categories of emotions because of the empirical evidence that supports their presence and relevance in sport settings (see, e.g. Jackson, 2000; Jones, 1995; Lane \& Terry, 2000). The emotions on the SEQ are measured in relation to an upcoming competition, rather than asking participants about the emotions they generally feel (Jones et al., 2005). In view of this observation, of the fluctuating and dynamic nature of emotions across context and time (Lazarus, 1999; Uphill, Groom, \& Jones, 2012), and the aforementioned importance of measuring organisation-related emotions, there is a need for research to test the SEQ in relation to the organisational environment and at other time points (e.g. the past month). 
Measures of emotions in an organisational environment have been previously developed in occupational psychology and human relations research (see, e.g. Daniels, 2000; Warr, 1990). However, the items in these questionnaires typically measure affective well-being and emotions, and have not been developed with reference to research in sport settings; therefore, accentuating the need to test the factor structure of the SEQ for usage in an organisational environment.

The original study designed to develop and validate the SEQ provided evidence for the questionnaire's psychometric properties, with particular reference to its reliability and face, concurrent and construct validity (Jones et al., 2005). In addition, support has been provided for the factorial validity of the SEQ (comparative fit index $(\mathrm{CFI})=.93$; root mean square error of approximation $($ RMSEA $)=.07)($ Jones et al., 2005). A shortcoming of these findings is that the same sample was used to refine the item pool and test the measurement model. It is, however, important to use different samples for these two purposes, to check that the pre-identified model structure is reliable and that the measure can produce consistent results when measuring the same entities under different conditions (cf. Brown, 2006; Field, 2009; Harrington, 2008). Research should, therefore, adopt a different sample to test the measure and also ensure that the sample demonstrates cultural diversity in view of Jones et al.'s (2005) acknowledged limitation of sampling UK athletes alone.

It is generally accepted that establishing the validity of a psychometric instrument is an ongoing process (cf. Kaplan \& Saccuzzo, 2012; Schutz \& Gessaroli, 1993). Therefore, in view of this observation and the preceding review of the emotion in sport literature, the purpose of this study was to test the factor structure of the SEQ in a sport organisational environment and during the past month of sport performers' lives. Second, the study examined if components of the SEQ measurement model were invariant across different groups of sport performers. Establishing factorial invariance enables researchers to make comparisons across groups and is of considerable 
importance for rigorous and robust psychological research (Estabrook, 2012). The theoretical rationale for examining invariance is related to the measurement of latent variables (Estabrook, 2012; van de Schoot, Lugtig, \& Hox, 2012). Specifically, to apply a factor analytic model to various groups, scholars use factorial invariance to establish the equivalence of relationships between the latent variable and the set of manifest variables across groups (Estabrook, 2012; see also, Byrne, 2006). By conducting such tests and having interpretable and meaningful latent variables, scholars are able to build sound theory (Estabrook, 2012). Specific to this study, we expected invariance in the measurement model since there is no evidence to suggest that the SEQ items or factorial structure should not operate equivalently across populations, and thus, we expect the measurement model to be group invariant (cf. Byrne, 2006).

\section{Method}

\section{Participants}

The sample consisted of 1277 sport performers (646 males and 631 females). They were aged between 18 and 78 years (mean $=25.79$ years, $s=10.34$ ), were of 25 nationalities and represented 45 sports. The participants had been competing at standards ranging from club to international for between 2 months and 65 years (mean $=11.58$ years, $s=8.64$ ).

\section{Measure}

SEQ (Jones et al., 2005). Sport performers' emotions were assessed using the 22 items from the SEQ. The items are categorised under five subscales: anxiety (five items: nervous, anxious, tense, apprehensive and uneasy), dejection (five items: unhappy, sad, upset, dejected and disappointed), anger (four items: annoyed, irritated, furious and angry), excitement (four items: enthusiastic, excited, energetic and exhilarated) and happiness (four items: joyful, pleased, cheerful and happy). On a 5-point Likert-type scale, that ranged from 0 (not at all) to 4 (extremely), participants were required to indicate how they had felt in their organisational environment during 
the past month. To further situate the completion of the SEQ within the context of the organisational environment, the participants were asked to complete the 23 -item Organizational Stressor Indicator for Sport Performers (OSI-SP; Arnold, Fletcher, \& Daniels, 2013) prior to completing the SEQ. The OSI-SP measures the frequency, intensity and duration of organisational stressors encountered over the past month. The organisational stressor data are not presented or discussed in this paper, since it is beyond the scope of the specific purpose for this study.

\section{Procedure}

Following institutional ethical approval, sport performers were recruited through either direct contact or via enquiries with coaches, clubs, sport organisations and event organisers. The participants were informed that any personally identifiable information they provided would be kept strictly confidential and, apart from the researchers, no one would have access to any individual responses. Data collection took place using online $(n=703)$ and paper $(n=574)$ versions of the SEQ. In accordance with guidelines in this area (cf. Lonsdale, Hodge, \& Rose, 2006), we adopted a sequential model testing approach via multi-sample confirmatory factor analysis to examine whether the measurement models for paper and online methods were invariant. The results highlighted that the change in comparative fit index values was $\leq .01$ in all the analyses (cf. Cheung \& Rensvold, 2002), therefore supporting the equality of factor loadings, variances and covariances on the SEQ across paper and online methods of data collection. As a result, paper and online data were merged before the analyses.

\section{Data analysis}

In addition to assessing the univariate skewness and kurtosis of the data, Mardia's normalised coefficient was examined for multivariate kurtosis. The data were found to depart from multivariate normality; therefore, all confirmatory factor analyses were conducted using the robust maximum likelihood estimation procedure with a Satorra-Bentler correction (S-B $\chi 2$; cf. Bentler \& 
Wu, 2002; West, Finch, \& Curran, 1995) and fit indices corrected for robust estimation. These confirmatory factor analyses were conducted using EQS 6.1 (Multivariate Software Inc., Encino, CA, USA) (Bentler \& Wu, 2002), with one item from each of the five factors fixed at 1.0 for the purposes of identification and latent variable scaling. In view of the ongoing debate regarding the evaluation of model fit (cf. McIntosh, 2012; Vernon \& Eysenck, 2007; Williams, Vandenberg, \& Edwards, 2009), the chi-square statistic and a variety of fit indices were used to evaluate the adequacy of the model to the data. The fit indices adopted were the CFI (Bentler, 1990), the Bentler-Bonett non-normed fit index (NNFI; Bentler \& Bonett, 1980) and RMSEA (Steiger, 1990). In the statistical literature, a value of $>.90$ for the CFI was originally considered acceptable (Bentler, 1992); however, Hu and Bentler (1999) proposed a revised cut-off value close to 95. Values for the NNFI should meet the above CFI guidelines to be considered acceptable, since the NNFI is a variant of the NFI (Byrne, 2006). It is generally accepted that an adequate fit between data and a hypothesised model is indicated by RMSEA values of around .06 (Hu \& Bentler, 1999).

These fit indices, however, are not immune to misspecification (cf. Heene, Hilbert, Draxler, Ziegler, \& Bühner, 2011; Marsh, Hau, \& Wen, 2004). As a result, the aforementioned criteria for fit indices were treated as guides rather than absolute values in the present study. In addition, the fit indices were used in combination with modification indices, standardised residuals and standardised factor loadings to analyse for model misspecification. The internal consistencies of the five factors were calculated using Cronbach's alpha coefficients.

To address the second purpose of this study, a sequential model testing approach was employed via multi-sample confirmatory factor analysis to examine whether the SEQ displayed invariance across different groups of sport performers. The demographic variables used were gender (male $(n=646)$ or female $(n=631))$, sport type (team $(n=316)$ or individual $(n=271))$, 
competitive standard (low $(n=497)$ or high $(n=655)$, where club and county are classified as low, and collegiate/ university, senior national and international are classified as high) and competitive experience (low $(n=696)$ or high $(n=572)$ based on a median split). Following the establishment of a baseline model for each variable, increasingly constrained models were devised to examine the equality of measurement (factor loadings) and structural parameters (factor variances and covariances) of the SEQ across the different groups (Byrne, 2006). In addition to adopting the $\Delta \mathrm{S}-\mathrm{B} \chi 2$ test statistic to indicate equality across groups, a CFI change of $\leq .01$ was used to indicate model invariance. This is because the $\chi 2$ difference test is oversensitive to multivariate normality, minor misspecifications and sample size, whereas the usage of the goodness- of-fit indexes to test measurement invariance has been widely supported (see, e.g. Chen, 2007; Cheung \& Rensvold, 2002).

\section{Results}

\section{Preliminary analyses}

Only $0.58 \%$ of the possible data points were missing in this study, and no variable on the SEQ had > 5\% missing data. The expectation maximisation algorithm was used to impute missing values. Table 1 displays the means and standard deviations of the 22 items and five subscales on the SEQ, as well as the skewness and kurtosis values of each item. For multivariate kurtosis, the data departed from normality (Mardia's normalised coefficient $=73.01)$.

\section{Main analyses}

Testing the SEQ factor structure. To address the first purpose of this study, confirmatory factor analyses were used to test the factor structure of the SEQ. Results of the initial confirmatory factor analysis indicated the following values: $\mathrm{S}-\mathrm{B} \chi 2(199)=1007.22, P<.001, \mathrm{CFI}=.93, \mathrm{NNFI}$ $=.92$, RMSEA $=.06$. These results show partial support for the hypothesised measurement model. Specifically, the fit values are acceptable if adopting the RMSEA and original CFI guidelines (cf. 
Bentler, 1992); however, in accordance with Hu and Bentler's (1999) revised CFI cutoff value, the model is close to the suggested values. It is worth noting, however, that these fit indices do indicate the same values (e.g. CFI) or better values (e.g. RMSEA) than those reported in the initial validation of the SEQ (cf. Jones et al., 2005). Notwithstanding this observation, these results suggest that the model fit could be improved; therefore, the modification indices were examined for model misspecification. These indices indicated that the nervous item should be allowed to not only load on the anxiety factor, but also additionally load on the dejection factor. Despite this suggestion, there appears to be no evidence supporting this cross-loading in previous research, nor any substantive or empirical rationale for the double loading effect. As a result, since items should ideally only target one underlying factor on a measurement tool (cf. Byrne, 2006), it was considered inappropriate to re-specify the model with this parameter freely estimated. Further suggestions from the LM $\chi 2$ statistic and related probability values were also not implemented, since they were either not substantively or empirically justified (e.g. cross loadings) or deemed inappropriate for preserving psychometric integrity (e.g. correlating error variances) (cf. Byrne, 2006; Jöreskog, 1993).

In measurement models where overall fit is not fully supported, researchers have suggested exploring the structure and assessing the psychometric properties of each factor independently (Brown, 2006; Harrington, 2008; Hurley et al., 1997; Mullan, Markland, \& Ingledew, 1997; Woodman \& Hardy, 2003). Measuring the factorial validity of subscales is also important practically, because practitioners will often calculate factor scores by averaging the items in a subscale (Lane, Harwood, Terry, \& Karageorghis, 2004; see also Grice, 2001; Stone, Ye, Zhu, \& Lane, 2009). Conducting a confirmatory factor analysis on each factor on the SEQ independently (see Table 2) revealed strong support for both the dejection and happiness subscales, with all fit values for these scales being acceptable or better than criteria fit indices. For the anger, anxiety and 
excitement subscales, some fit values demonstrated room for improvement (e.g. the anger, anxiety and excitement RMSEA values, and the anger NNFI value).

All five subscales on the SEQ demonstrated acceptable internal consistency (anxiety $\alpha=$ .85 , dejection $\alpha=.87$, anger $\alpha=.87$, excitement $\alpha=.77$ and happiness $\alpha=.85$ ) (see Table 3). Table 3 also illustrates that the correlations between the five latent variables ranged from -.02 to $.73(95 \%$ CI $[.09, .44])$. Since none of these values or their $95 \%$ CI range encompass 1.00 , this finding provides evidence for the discriminant validity of the factors. It is also worth noting that the anxiety factor significantly correlated with the dejection (.47), anger (.36), excitement (.24) and happiness (.16) factors. In addition, there was a statistically significant correlation between the anger and dejection (.73) and excitement and happiness factors (.72).

As suggested in the confirmatory factor analysis literature (see Byrne, 2006; Jackson, Gillaspy, \& Purc-Stephenson, 2009), alternative models were run to determine if the first-order, five-factor, 22- item model demonstrated the best fit to the observed data. First, a hierarchical model was tested in which the five first-order factors were represented by one higher-order factor. The fit of the hierarchical measurement model was worse than the 22-item model: S-B $\chi 2(204)=$ $1801.82, P<.01, \mathrm{CFI}=.88, \mathrm{NNFI}=.86, \mathrm{RMSEA}=.08$. Second, a one-factor model was tested (with all 22-items), which produced a very poor fit to the data: $\mathrm{S}-\mathrm{B} \chi 2(209)=7318.14, P<.01$, $\mathrm{CFI}=.47, \mathrm{NNFI}=.41, \mathrm{RMSEA}=.16$. Third, a two-factor model separating emotions into those which were considered more pleasant/positive or unpleasant/negative (cf. Jones et al., 2005; McCarthy, 2011) produced a fit that was better than the one-factor model, but worse than the original five-factor and hierarchical models: $\mathrm{S}-\mathrm{B} \chi 2(208)=3266.06, P<.01, \mathrm{CFI}=.78, \mathrm{NNFI}=$ $.74, \mathrm{RMSEA}=.11$

Invariance testing. There were three significant changes in the $\mathrm{S}-\mathrm{B} \chi 2$ difference test, which occurred when the factor loadings $(\Delta S-B \chi 2=41.63)$, factor variances $(\Delta S-B \chi 2=54.01)$ and 
factor covariances $(\Delta S-B \chi 2=62.51)$ were constrained across gender. In accordance with Cheung and Rensvold's (2002) guidelines, the change in CFI values was $\leq .01$ in all the analyses (see Table 4). These results provide support for the equality of factor loadings, variances and covariances on the SEQ across gender, sport type, competitive standard and competitive experience.

\section{Discussion}

The SEQ can serve numerous functions for research and practice in sport psychology. For research, the SEQ can be used to compare and contrast sport performers' emotions, assess changes in emotions over time and evaluate the effectiveness of emotion-related interventions. For practice, the SEQ can be used to enhance practitioners' awareness of the emotions that are being experienced by sport performers, so that individualised interventions can be designed and delivered. The utility of a psychometric instrument does, however, depend on it demonstrating appropriate validity and reliability (cf. DeVellis, 2003; Gillham, 2004). The results of the present study support the validity and reliability of the SEQ when, in accordance with the first purpose of this study, it is used in a sport organisational environment and during the past month of sport performers' lives. The utility of the measure is further supported in the present study because, by investigating the second purpose, components of the SEQ measurement model were found to be invariant across different groups of sport performers. The significant factor loadings and high internal consistencies of the subscales further support the validity, reliability and utility of the SEQ in the present study, suggesting that the measure is conceptually well designed and relevant to sport performers.

To elaborate on the findings in relation to the first purpose of this study, support was provided for the factorial validity of the SEQ. Specifically, the fit indices for the five-factor structure demonstrate partial support for the hypothesised measurement model by meeting original CFI and RMSEA guidelines (cf. Bentler, 1992). In comparison with the initial validation of the 
SEQ, these fit indices are either equal to $($ e.g. $\mathrm{CFI}=.93)$ or better than $($ e.g. RMSEA $=.06)$ the original results reported by Jones et al. (2005). Notwithstanding this improvement, establishing the validity of a psychometric instrument is an ongoing process (cf. Kaplan \& Saccuzzo, 2012; Schutz \& Gessaroli, 1993); therefore, future research should continue to test the factorial validity of the SEQ, since it did not meet Hu and Bentler's (1999) revised cut-off value. In addition, it would be insightful for future research to test other forms of validity of the SEQ (e.g. convergent/divergent) as well as its test-retest reliability.

In future developments of the measure, it may be the case that further emotions are incorporated into the items, based on those identified in the early stages of the SEQ's development (cf. Jones et al., 2005) or those that have been identified within the organisational environment in sport (see, e.g. Fletcher et al., 2012). To elaborate on the latter point, Fletcher et al. (2012) identified various emotions that are deemed salient in organisational environments that are not present in the 22-item SEQ (e.g. hope, relief, reproach, resentment). Another avenue for future research is to investigate if there are any differences in the presence and relevance of emotions across different sport environments and time points. For example, when comparing the emotions experienced during the past month in organisational environments in the present study with the pre-competitive emotions reported in previous research (cf. Jones et al., 2005), it is evident that all of the emotion factors have a higher mean value in the present study. This finding underscores the importance of not only examining emotions and, subsequently, intervening with athletes just before competition, but also recognising and addressing the prevalence of emotions at different time points and in organisational environments in sport. Following on from this, future research should also look to use the SEQ to determine the exact information that emotions experienced in relation to an organisational environment can add in explaining a sport performer's performance and wellbeing, over and above that explained by emotions experienced in response to competitive 
environments.

The results of the present study at the subscale level illustrate that all of the factors have acceptable CFI values (Hu \& Bentler, 1999). For the anger, anxiety and excitement factors, however, some of the values for other fit indices demonstrate room for improvement. For example, the anger subscale displays a higher than acceptable RMSEA value, which could perhaps be because the irritated item displays a lower factor loading than in the original validation study (.70 compared to .75) or because of the significant correlation between the anger and anxiety (.36) or anger and dejection (.73) subscales. Indeed, absolute misfit indexes, such as the RMSEA, decrease as the goodness of fit improves and are sensitive to the complexity of a model (cf. Browne, MacCallum, Kim, Andersen, \& Glaser, 2002; Byrne, 2006). Therefore, lower factor loadings or high correlations on the SEQ may create a decreased goodness of fit or modify the complexity of the model and, in doing so, result in a higher RMSEA value. The RMSEA value for the anxiety subscale (.07) was only marginally higher than acceptable values (cf. Hu \& Bentler, 1999). This could perhaps be explained by the lower factor loadings of some items (e.g. nervous, tense, uneasy) compared to Jones et al.'s (2005) initial validation study or by the significant correlations between the anxiety subscale and other factors. These correlations are comparable to those observed by Jones et al. (2005). Furthermore, similar correlations are also evident in research on competitive anxiety in sport (see, e.g. Jones \& Hanton, 2001), whereby a performer's anxiety is significantly related to positive or negative emotions dependent on how the anxiety is interpreted.

The higher than recommended RMSEA value for the excitement factor (.09) could be explained by some factor loadings (e.g. excited, energetic, exhilarated) being lower than in the initial validation study (Jones et al., 2005). Alternatively, this value could be explained by the significant correlation between the excitement and happiness factors (.72). A similar correlation between happiness and excitement is evident in Jones et al.'s (2005) initial validation study and in 
personality and social psychology (Mogilner, Kamvar, \& Aaker, 2011), consumer behaviour (Mogilner, Aaker, \& Kamvar, 2012) and marriage and family research (Harry, 1976). Despite the significant correlations discussed between various factors on the SEQ, this study has provided evidence for the discriminant validity of the factors, thus indicating that they are unique constructs representing different facets of emotions.

The relatively high inter-correlations between some of the factors on the SEQ suggest that a second-order model could be plausible. The results, however, revealed that the fit of the hierarchical model was worse than the first-order, five-factor structure. As a result of this finding, it is suggested that although the hierarchical structure may be more parsimonious if a general measure of emotions is required (cf. Li \& Harmer, 1996; Marsh, 1987), the first-order, five-factor model provides the best fit and is most applicable for a more in-depth assessment of emotions. One-factor and two-factor models were also tested, with results demonstrating that these structures also displayed a worse fit to the data than the first-order, five-factor model. These findings suggest that emotions are a multifactorial construct that are best represented by a number of separate, albeit related, emotion factors.

For the second purpose of this study, the factorial invariance of the measurement model was tested and it was found that the factor loadings, variances and covariances were equivalent across gender, sport type, competitive standard and competitive experience. As a result of this factorial invariance, researchers can now be assured that the constructs presumed to drive responses to the SEQ items are the same across different groups (Williams, Edwards, \& Vandenberg, 2003) and meaningful comparisons can be made between sport performers (Vandenberg \& Lance, 2000; van de Schoot et al., 2012). To further test the measurement invariance of the SEQ in the future, researchers could use exploratory structural equation modelling to test the invariance of indicator intercepts, item uniqueness and latent mean 
differences (see, e.g. Marsh et al., 2009; Millsap, 2011; Morin, Marsh, \& Nagengast, 2013).

Future research in this area of enquiry should utilise longitudinal designs, as opposed to those of a cross-sectional nature, to better capture the transient and fluctuating nature of emotions across contexts and over time. Although the present study validates the SEQ at a different time point from the original validation (e.g. over the past month in comparison with an upcoming competition), future research should also examine the longitudinal invariance of the measure (cf. Kim \& Ji, 2008) based on two or more waves of data separated by a meaningful time frame for sport engagement. To provide a more detailed assessment of emotions within these designs, researchers should perhaps extend the SEQ from assessing solely the presence of emotions, to also measuring dimensions such as frequency, intensity and duration, and perhaps also the orientation in which emotions are interpreted (cf. Arnold \& Fletcher, 2012a; Arnold et al., 2013; Martinent et al., 2012; Mellalieu, Hanton, \& Fletcher, 2006). In future, it will also be important for researchers to not only examine the emotions felt in organisational environments, but also investigate the emotions expressed in this environment. To elaborate, research in organisational psychology on emotional labour suggests that in any organisational setting, there are emotions that individuals are expected to express (according to display rules) and those which are actually expressed (according to feeling rules) (cf. Ashforth \& Humphrey, 1993; Ashkanasy \& Daus, 2013; Diefendorff \& Gosserand, 2003; Hochschild, 1983). As a result of this distinction and the effect that emotional labour can have on the well-being and performance of individuals (see, e.g. Adelmann, 1995; Wharton, 1993), future researchers should develop a measure that can assess the emotions displayed in sport settings (cf. Brotheridge \& Lee, 2003).

Once reliable measurement strategies have been developed and validated, sport psychology researchers will be in a better position to investigate the relationships between felt and displayed emotions in organisational environments and their potential antecedents. One example antecedent 
may be that of stress mindsets which, referring to an individual's belief about the potential of stress to have either enhancing or debilitative consequences, has been identified as an influential variable in determining stress responses in personality and social psychology research (cf. Crum, Salovey, \& Achor, 2013). In addition to the link between emotions and antecedents, valid and reliable measurement strategies will also enable scholars to investigate the relationship between felt and displayed emotions in organisational environments and athletes' performances in training and competition. This is an important future research direction, since emotions have been suggested to influence performance in sport (see, e.g. Uphill et al., 2012); however, the exact nature of and mechanisms underpinning this relationship are not yet fully understood, particularly in response to organisational events.

To conclude, this study has provided support for the reliability and validity of the SEQ for measuring the emotions that sport performers have encountered in an organisational environment during the past month. As a result of this study, the SEQ now offers a window of investigation with which interesting future research questions can be explored, and, ultimately, a better understanding of emotions in organisational environments achieved. 


\section{References}

Adelmann, P. K. (1995). Emotional labor as a potential source of job stress. In S. L. Sauter \& L. R. Murphy (Eds.), Organizational risk factors for stress (pp. 371-381). Washington, DC: American Psychological Association.

Arnold, R., \& Fletcher, D. (2012a). Psychometric issues in organizational stressor research: A review and implications for sport psychology. Measurement in Physical Education and Exercise Science, 16, 81-100.

Arnold, R., \& Fletcher, D. (2012b). A research synthesis and taxonomic classification of the organizational stressors encountered by sport performers. Journal of Sport and Exercise Psychology, 34, 397-429.

Arnold, R., Fletcher, D., \& Daniels, K. (2013). Development and validation of the Organizational Stressor Indicator for Sport Performers (OSI-SP). Journal of Sport and Exercise Psychology, 35, 180-196.

Ashforth, B. E., \& Humphrey, R. H. (1993). Emotional labor in service roles: The influence of identity. Academy of Management Review, 18, 88-115.

Ashkanasy, N. M., \& Daus, C. S. (2013). Emotional labor in the 21st century: Diverse perspectives on emotion regulation at work. In A. A. Grandey, J. M. Diefendorff, \& D. E. Rupp (Eds.), Emotional labor across five levels of analysis: Past, present, future (pp. 282-288). Hove: Routledge.

Bentler, P. M. (1990). Comparative fit indexes in structural models. Psychological Bulletin, 107, 238-246.

Bentler, P. M. (1992). On the fit of models to covariances and methodology to the Bulletin. Psychological Bulletin, 112, 400-404.

Bentler, P. M., \& Bonett, D. G. (1980). Significance tests and goodness of fit in the analysis of 
covariance structures. Psychological Bulletin, 88, 588-606.

Bentler, P. M., \& Wu, E. J. C. (2002). EQS 6 for Windows: User's guide. Encino, CA: Multivariate Software.

Brotheridge, C. M., \& Lee, R. T. (2003). Development and validation of the Emotional Labour Scale. Journal of Occupational and Organizational Psychology, 76, 365-379.

Brown, T. A. (2006). Confirmatory factor analysis for applied research. New York, NY: Guilford Press.

Browne, M. W., MacCallum, R. C., Kim, C.-T., Andersen, B. L., \& Glaser, R. (2002). When fit indices and residuals are incompatible. Psychological Methods, 7, 403-421.

Brunelle, J. P., Janelle, C. M., \& Tennant, L. K. (1999). Controlling competitive anger among male soccer players. Journal of Applied Sport Psychology, 11, 283-297.

Byrne, B. M. (2006). Structural equation modelling with EQS: Basic concepts, applications, and programming. London: Lawrence Erlbaum.

Chen, F. F. (2007). Sensitivity of goodness of fit indexes to lack of measurement invariance. Structural Equation Modeling: A Multidisciplinary Journal, 14, 464-504.

Cheung, G. W., \& Rensvold, R. B. (2002). Evaluating goodness- of-fit indexes for testing measurement invariance. Structural Equation Modeling: A Multidisciplinary Journal, 9, 233255.

Crum, A. J., Salovey, P., \& Achor, S. (2013). Rethinking stress: The role of mindsets in determining the stress response. Journal of Personality and Social Psychology, 104, 716-733.

Daniels, K. (2000). Measures of five aspects of affective well-being at work. Human Relations, 53, 275-294.

DeVellis, R. F. (2003). Scale development: Theory and applications. Thousand Oaks, CA: Sage. Diefendorff, J. M., \& Gosserand, R. H. (2003). Understanding the emotional labor process: A 
control theory perspective. Journal of Organizational Behavior, 24, 945-959.

Duffy, E. (1934). Is emotion a mere term of convenience? Psychological Review, 41, 103-104.

Estabrook, R. (2012). Factorial invariance: Tools and concepts for strengthening research. In G.

Tenenbaum, R. C. Eklund, \& A. Kamata (Eds.), Measurement in sport and exercise psychology (pp. 53-63). Champaign, IL: Human Kinetics.

Field, A. (2009). Discovering statistics using SPSS. London: Sage.

Fletcher, D., Hanton, S., \& Mellalieu, S. D. (2006). An organizational stress review: Conceptual and theoretical issues in competitive sport. In S. Hanton \& S. D. Mellalieu (Eds.), Literature reviews in sport psychology (pp. 321-373). Hauppauge, NY: Nova Science.

Fletcher, D., Hanton, S., \& Wagstaff, C. R. D. (2012). Performers' responses to stressors encountered in sport organisations. Journal of Sports Sciences, 30, 349-358.

Fredrickson, B. L. (2001). The role of positive emotions in positive psychology: The broaden-andbuild theory of positive emotions. American Psychologist, 56, 218-226.

Gendron, M. (2010). Defining emotion: A brief history. Emotion Review, 2, 371-372.

Gillham, B. (2004). Developing a questionnaire. London: Continuum.

Gould, D., Guinan, D., Greenleaf, C., Medbery, R., \& Peterson, K. (1999). Factors affecting Olympic performance: Perceptions of athletes and coaches from more and less successful teams. The Sport Psychologist, 13, 371-394.

Grice, J. W. (2001). Computing and evaluating factor scores. Psychological Methods, 6, 430-450.

Hanin, Y. L. (2000). Successful and poor performance emotions. In Y. L. Hanin (Eds.), Emotions in sport (pp. 157-187). Champaign, IL: Human Kinetics.

Hanin, Y. L. (2007). Emotions in sport: Current issues and perspectives. In G. Tenenbaum \& R. C. Eklund (Eds.), Handbook of sport psychology (pp. 31-58). Hoboken, NJ: John Wiley \& Sons.

Hanton, S., Fletcher, D., \& Coughlan, G. (2005). Stress in elite sport performers: A comparative 
study of competitive and organizational stressors. Journal of Sports Sciences, 23, 1129-1141.

Harrington, D. (2008). Confirmatory factor analysis. Oxford: Oxford University Press.

Harry, J. (1976). Evolving sources of happiness for men over the life cycle: A structural analysis. Journal of Marriage and The Family, 38, 289-296.

Heene, M., Hilbert, S., Draxler, C., Ziegler, M., \& Bühner, M. (2011). Masking misfit in confirmatory factor analysis by increasing unique variances: A cautionary note on the usefulness of cutoff values of fit indices. Psychological Methods, 16, 319-336.

Hochschild, A. R. (1983). The managed heart: Commercialization of human feeling. Berkeley: University of California Press.

Hu, L., \& Bentler, P. M. (1999). Cutoff criteria for fit indexes in covariance structure analysis: Conventional criteria versus new alternatives. Structural Equation Modeling: A Multidisciplinary Journal, 6, 1-55.

Hurley, A. E., Scandura, T. A., Schriesheim, C. A., Brannick, M. T., Seers, A., Vandenberg, R. J., \& Williams, L. J. (1997). Exploratory and confirmatory factor analysis: Guidelines, issues, and alternatives. Journal of Organizational Behavior, 18, 667-683.

Izard, C. E. (2010). The many meanings/aspects of emotion: Definitions, functions, activation, and regulation. Emotion Review, 2, 363-370.

Jackson, D. L., Gillaspy, J. A., \& Purc-Stephenson, R. (2009). Reporting practices in confirmatory factor analysis: An overview and some recommendations. Psychological Methods, 14, 6-23.

Jackson, S. A. (2000). Joy, fun, and flow state in sport. In Y. L. Hanin (Ed.), Emotions in sport (pp. 135-155). Champaign, IL: Human Kinetics.

Jones, G. (1995). More than just a game: Research developments and issues in competitive anxiety in sport. British Journal of Psychology, 86, 449-478.

Jones, G., \& Hanton, S. (2001). Pre-competitive feeling states and directional anxiety 
interpretations. Journal of Sports Sciences, 19, 385-395.

Jones, M. V., Lane, A. M., Bray, S. R., Uphill, M., \& Catlin, J. (2005). Development and validation of the Sport Emotion Questionnaire. Journal of Sport and Exercise Psychology, 27, 407-431.

Jones, M. V., \& Uphill, M. A. (2011). Emotions in sport: Antecedents and performance consequences. In J. Thatcher, M. Jones, \& D. Lavallee (Eds.), Coping and emotion in sport (2nd ed., pp. 33-61). London: Routledge.

Jöreskog, K. G. (1993). Testing structural equation models. In K. A. Bollen \& J. S. Long (Eds.), Testing structural equation models (pp. 294-316). Newbury Park, CA: Sage.

Kaplan, R. M., \& Saccuzzo, D. P. (2012). Psychological testing: Principles, applications, and issues. Belmont, CA: Wadsworth Cengage Learning.

Kim, H., \& Ji, J. (2008). Factor structure and longitudinal invariance of the Maslach Burnout Inventory. Research on Social Work Practice, 19, 325-339.

Lane, A. M., Harwood, C., Terry, P. C., \& Karageorghis, C. I. (2004). Confirmatory factor analysis of the Test of Performance Strategies (TOPS) among adolescent athletes. Journal of Sports Sciences, 22, 803-812.

Lane, A. M., \& Terry, P. C. (2000). The nature of mood: Development of a conceptual model with a focus on depression. Journal of Applied Sport Psychology, 12, 16-33.

Lazarus, R. S. (1999). Stress and emotion: A new synthesis. New York, NY: Springer.

Lazarus, R. S. (2000). How emotions influence performance in competitive sports. The Sport Psychologist, 14, 229-252.

Lazarus, R. S., \& Folkman, S. (1984). Stress, appraisal, and coping. New York, NY: Springer. Li, F., \& Harmer, P. (1996). Confirmatory factor analysis of the Group Environment Questionnaire with an intercollegiate sample. Journal of Sport and Exercise Psychology, 18, 49-63. 
Lonsdale, C., Hodge, K., \& Rose, E. A. (2006). Pixels vs. paper: Comparing online and traditional survey methods in sport psychology. Journal of Sport and Exercise Psychology, 28, 100-108.

Marsh, H. W. (1987). The hierarchical structure of self-concept and the application of hierarchical confirmatory factor analysis. Journal of Educational Measurement, 24, 17-39.

Marsh, H. W., Hau, K.-T., \& Wen, Z. (2004). In search of golden rules: Comment on hypothesistesting approaches to setting cutoff values for fit indexes and dangers in overgeneralizing $\mathrm{Hu}$ and Bentler's (1999) findings. Structural Equation Modeling: A Multidisciplinary Journal, $11,320-341$.

Marsh, H. W., Muthén, B., Asparouhov, T., Lüdtke, O., Robitzsch, A., Morin, A. J. S., \& Trautwein, U. (2009). Exploratory structural equation modeling, integrating CFA and EFA: Application to students' evaluations of university teaching. Structural Equation Modeling: A Multidisciplinary Journal, 16, 439-476.

Martens, R., Burton, D., Vealey, R. S., Bump, L., \& Smith, D. E. (1990). Development and validation of the Competitive Sports Anxiety Inventory-2. In R. Martens, R. S. Vealey, \& D. Burton (Eds.), Competitive anxiety in sport (pp. 117-178). Champaign, IL: Human Kinetics. Martinent, G., Campo, M., \& Ferrand, C. (2012). A descriptive study of emotional process during competition: Nature, frequency, direction, duration and co-occurrence of discrete emotions. Psychology of Sport and Exercise, 13, 142-151.

Maxwell, J. P., \& Moores, E. (2007). The development of a short scale measuring aggressiveness and anger in competitive athletes. Psychology of Sport and Exercise, 8, 179-193.

McCarthy, P. J. (2011). Positive emotion in sport performance: Current status and future directions. International Review of Sport and Exercise Psychology, 4, 50-69.

McIntosh, C. N. (2012). Improving the evaluation of model fit in confirmatory factor analysis: A commentary on Gundy, C. M., Fayers, P. M., Groenvold, M., Petersen, M. Aa., Scott, N. W., 
Sprangers, M. A. J., Velikov, G., \& Aaronson, N. K. (2011). Comparing higher-order models for the EORTC QLQ-C30. Quality of Life Research, doi:10.1007/s11136-011-0082-6. Quality of Life Research, 21, 1619-1621.

Meehan, H. L., Bull, S. J., Wood, D. M., \& James, D. V. B. (2004). The overtraining syndrome: A multi-contextual assessment. The Sport Psychologist, 18, 154-171.

Mellalieu, S. D., Hanton, S., \& Fletcher, D. (2006). A competitive anxiety review: Recent directions in sport psychology research. In S. Hanton \& S. D. Mellalieu (Eds.), Literature reviews in sport psychology (pp. 1-45). Hauppauge, NY: Nova Science.

Millsap, R. E. (2011). Statistical approaches to measurement invariance. New York, NY: Routledge.

Mogilner, C., Aaker, J., \& Kamvar, S. (2012). How happiness affects choice. Journal of Consumer Research, 39, 429-443.

Mogilner, C., Kamvar, S., \& Aaker, J. (2011). The shifting meaning of happiness. Social Psychological and Personality Science, 2, 395-402.

Morin, A. J. S., Marsh, H. W., \& Nagengast, B. (2013). Exploratory structural equation modeling. In G. R. Hancock \& R. O. Mueller (Eds.), Structural equation modeling: A second course (2nd ed.). Charlotte, NC: Information Age.

Mullan, E., Markland, D., \& Ingledew, D. K. (1997). A graded conceptualisation of selfdetermination in the regulation of exercise behaviour: Development of a measure using confirmatory factor analytic procedures. Personality and Individual Differences, 23, 745752.

Noblet, A., Rodwell, J., \& McWilliams, J. (2003). Predictors of the strain experienced by professional Australian footballers. Journal of Applied Sport Psychology, 15, 184-193.

Raglin, J. S., \& Hanin, Y. L. (2000). Competitive anxiety. In Y. L. Hanin (Ed.), Emotions in sport 
(pp. 39-63). Champaign, IL: Human Kinetics.

Schutz, R. W., \& Gessaroli, M. E. (1993). Use, misuse, and disuse of psychometrics in sport psychology research. In R. N. Singer, M. Murphey, \& L. K. Tennant (Eds.), Handbook of research on sport psychology (pp. 901-921). New York, NY: Macmillan.

Steiger, J. H. (1990). Structural model evaluation and modification: An interval estimation approach. Multivariate Behavioral Research, 25, 173-180.

Stone, C. A., Ye, F., Zhu, X., \& Lane, S. (2009). Providing subscale scores for diagnostic information: A case study when the test is essentially unidimensional. Applied Measurement in Education, 23, 63-86.

Tabei, Y., Fletcher, D., \& Goodger, K. (2012). The relationship between organizational stressors and athlete burnout in soccer players. Journal of Clinical Sport Psychology, 6, 146-165.

Uphill, M., Groom, R., \& Jones, M. (2012). The influence of in-game emotions on basketball performance. European Journal of Sport Science, 14, 76-83.

Vallerand, R. J. (1983). On emotion in sport: Theoretical and social psychological perspectives. Journal of Sport Psychology, 5, 197-215.

Vallerand, R. J., \& Blanchard, C. M. (2000). The study of emotion in sport and exercise. In Y. L. Hanin (Eds.), Emotions in sport (pp. 3-38). Champaign, IL: Human Kinetics.

Van De Schoot, R., Lugtig, P., \& Hox, J. (2012). A checklist for testing measurement invariance. European Journal of Developmental Psychology, 9, 486-492.

Vandenberg, R. J., \& Lance, C. E. (2000). A review and synthesis of the measurement invariance literature: Suggestions, practices, and recommendations for organizational research. Organizational Research Methods, 3, 4-70.

Vernon, T., \& Eysenck, S. (2007). Structural equation modelling [Special issue]. Personality and Individual Differences, 42(5), 813-898. 
Wagstaff, C. R. D., Fletcher, D., \& Hanton, S. (2012). Exploring emotion abilities and regulation strategies in sport organizations. Sport, Exercise, and Performance Psychology, 1, 268-282.

Warr, P. (1990). The measurement of well-being and other aspects of mental health. Journal of Occupational Psychology, 63, 193-210.

West, S. G., Finch, J. F., \& Curran, P. J. (1995). Structural equation models with non-normal variables. Problems and remedies. In R. H. Hoyle (Ed.), Structural equation modelling: Concepts, issues, and applications (pp. 56-75). Newbury Park, CA: Sage.

Wharton, A. S. (1993). The affective consequences of service work: Managing emotions on the job. Work and Occupations, 20, 205-232.

Williams, L. J., Edwards, J. R., \& Vandenberg, R. J. (2003). Recent advances in causal modeling methods for organizational and management research. Journal of Management, 29, 903-936.

Williams, L. J., Vandenberg, R. J., \& Edwards, J. R. (2009). Structural equation modeling in management research: A guide for improved analysis. The Academy of Management Annals, 3, 543-604.

Woodman, T., \& Hardy, L. (2003). The relative impact of cognitive anxiety and self-confidence upon sport performance: A meta-analysis. Journal of Sports Sciences, 21, 443-457. 
Table 1: Descriptive Statistics for the Sport Emotion Questionnaire Items and Subscales

\begin{tabular}{|c|c|c|c|c|c|}
\hline Variable & M & $\mathrm{SD}$ & Factor Loading (Subscale) & Skewness & Kurtosis \\
\hline \multicolumn{6}{|l|}{ Items } \\
\hline 1. Uneasy & 1.10 & .98 & $.50(1)$ & .77 & .11 \\
\hline 2. Upset & 1.21 & 1.16 & $.71(2)$ & .74 & .35 \\
\hline 3. Exhilarated & 2.62 & 1.10 & $.58(3)$ & .69 & .10 \\
\hline 4. Irritated & 1.88 & 1.19 & $.70(4)$ & .10 & .92 \\
\hline 5. Pleased & 2.85 & .93 & $.71(5)$ & .64 & .13 \\
\hline 6. Tense & 2.19 & 1.18 & $.71(1)$ & .07 & .93 \\
\hline 7. $\mathrm{Sad}$ & 1.02 & 1.13 & $.75(2)$ & 1.00 & .11 \\
\hline 8. Excited & 2.89 & 1.01 & $.74(3)$ & .78 & .09 \\
\hline 9. Furious & 1.18 & 1.30 & $.77(4)$ & .84 & .48 \\
\hline 10. Joyful & 2.46 & 1.09 & $.76(5)$ & .38 & .46 \\
\hline 11. Nervous & 2.39 & 1.22 & $.79(1)$ & .27 & .94 \\
\hline 12. Unhappy & 1.10 & 1.12 & $.82(2)$ & .89 & .02 \\
\hline 13. Enthusiastic & 2.91 & .95 & $.76(3)$ & .65 & .01 \\
\hline 14. Annoyed & 1.74 & 1.21 & $.84(4)$ & .27 & .90 \\
\hline 15. Cheerful & 2.50 & .97 & $.77(5)$ & .34 & .33 \\
\hline 16. Apprehensive & 1.93 & 1.18 & $.79(1)$ & .07 & .90 \\
\hline 17. Disappointed & 1.83 & 1.22 & $.75(2)$ & .27 & .93 \\
\hline 18. Energetic & 2.81 & .95 & $.65(3)$ & .52 & .23 \\
\hline 19. Angry & 1.31 & 1.26 & $.85(4)$ & .68 & .62 \\
\hline 20. Happy & 2.79 & .97 & $.83(5)$ & .60 & .06 \\
\hline 21. Anxious & 1.87 & 1.20 & $.86(1)$ & .16 & .88 \\
\hline 22. Dejected & 1.00 & 1.16 & $.74(2)$ & 1.05 & .18 \\
\hline \multicolumn{6}{|l|}{ Subscales } \\
\hline 1. Anxiety & 1.90 & .91 & N/A & N/A & N/A \\
\hline 2. Dejection & 1.23 & .94 & N/A & N/A & N/A \\
\hline 3. Anger & 1.52 & 1.05 & N/A & N/A & N/A \\
\hline 4. Excitement & 2.81 & 1.05 & N/A & N/A & N/A \\
\hline 5. Happiness & 2.65 & .82 & N/A & N/A & N/A \\
\hline
\end{tabular}


Table 2: Confirmatory Factor Analysis of the Sport Emotion Questionnaire Subscales

\begin{tabular}{lcccc}
\hline \multicolumn{1}{c}{ Subscale } & S-B $\chi^{2}$ & CFI & NNFI & RMSEA (CI) \\
\hline Anxiety & 38.10 & .99 & .97 & $.07(.05$ to .09$)$ \\
Dejection & 26.67 & .99 & .98 & $.06(.04$ to .08$)$ \\
Anger & 80.41 & .96 & .89 & $.18(.14$ to .21$)$ \\
Excitement & 22.00 & .98 & .94 & $.09(.06$ to .12$)$ \\
Happiness & 11.15 & .99 & .98 & $.06(.03$ to .10$)$ \\
\hline
\end{tabular}

Table 3: Correlations and Alpha Coefficients for the Sport Emotion Questionnaire Subscales

\begin{tabular}{lccccc}
\hline \multicolumn{1}{c}{ Subscale } & Anxiety & Dejection & Anger & Excitement & Happiness \\
\hline Anxiety & .85 & & & & \\
Dejection & $.47^{*}$ & .87 & & & \\
Anger & $.36^{*}$ & $.73^{*}$ & .87 & .77 & \\
Excitement & $.24^{*}$ & -.02 & .03 & $.72^{*}$ & .85 \\
Happiness & $.16^{*}$ & -.08 & .01 & & \\
\hline
\end{tabular}

Note. Cronbach's alpha $(\alpha)$ appears on the matrix diagonal. Pearson $r$ 's appear below the matrix diagonal $(* P<.01)$. 
Table 4: Sport Emotion Questionnaire Fit Indices for Invariance Analysis

\begin{tabular}{|c|c|c|c|c|c|c|c|c|}
\hline Model & $S-B \chi^{2}$ & $\mathrm{df}$ & RCFI & SRMR & RRMSEA & $\Delta \mathrm{S}-\mathrm{B} \chi^{2}$ & $\Delta \mathrm{df}$ & $\triangle \mathrm{RCFI}$ \\
\hline \multicolumn{9}{|l|}{ Gender } \\
\hline Unconstrained & $1211.23 *$ & 398 & .934 & .055 & .040 & - & - & - \\
\hline Constrained factor loadings & $1254.90 *$ & 415 & .932 & .057 & .040 & $41.63^{*}$ & 17 & .002 \\
\hline Constrained factor variances & $1268.00 *$ & 420 & .931 & .061 & .040 & $54.01 *$ & 5 & .001 \\
\hline Constrained factor covariances & $1279.07 *$ & 430 & .931 & .063 & .039 & $62.51 *$ & 10 & .000 \\
\hline \multicolumn{9}{|l|}{ Sport Type } \\
\hline Unconstrained & $721.08 *$ & 398 & .941 & .063 & .037 & - & - & - \\
\hline Constrained factor loadings & $740.48 *$ & 415 & .941 & .065 & .037 & 16.86 & 17 & .000 \\
\hline Constrained factor variances & $745.89 *$ & 420 & .941 & .071 & .036 & 22.08 & 5 & .000 \\
\hline Constrained factor covariances & $761.55^{*}$ & 430 & .940 & .075 & .036 & 38.29 & 10 & .001 \\
\hline \multicolumn{9}{|l|}{ Competitive Standard } \\
\hline Unconstrained & $1179.39 *$ & 398 & .929 & .055 & .041 & - & - & - \\
\hline Constrained factor loadings & $1208.61 *$ & 415 & .928 & .057 & .041 & 24.16 & 17 & .001 \\
\hline Constrained factor variances & $1216.38 *$ & 420 & .928 & .059 & .041 & 29.75 & 5 & .000 \\
\hline Constrained factor covariances & $1223.68 *$ & 430 & .928 & .063 & .040 & 36.34 & 10 & .000 \\
\hline \multicolumn{9}{|l|}{ Competitive Experience } \\
\hline Unconstrained & $1194.79 *$ & 398 & .934 & .052 & .040 & - & - & - \\
\hline Constrained factor loadings & $1217.01 *$ & 415 & .934 & .054 & .039 & 15.44 & 17 & .000 \\
\hline Constrained factor variances & $1226.43 *$ & 420 & .934 & .058 & .039 & 23.40 & 5 & .000 \\
\hline Constrained factor covariances & $1236.81 *$ & 430 & .934 & .059 & .038 & 34.15 & 10 & .000 \\
\hline
\end{tabular}

Note. $\mathrm{S}-\mathrm{B} \chi^{2}=$ Satorra-Bentler scaled chi-square statistic, $\mathrm{df}=$ degrees of freedom, $\mathrm{RCFI}=$ robust comparative fit index, $\mathrm{SRMR}=$ standardized root mean residual, RRMSEA = robust root mean square error of approximation, $\Delta \mathrm{S}-\mathrm{B} \chi^{2}=\mathrm{Satorra}-\mathrm{Bentler}$ scaled chisquare difference, $\Delta \mathrm{df}=$ difference in degrees of freedom, $\Delta \mathrm{RCFI}=$ change in RCFI, when the fit of the more constrained model is compared with that of the previous less constrained model (Cheung \& Rensvold, 2002). $* P<.01$. 